\title{
Bellek Tasnifleri ve Dil Eğitimine Yansımaları: Dil Bilmek Ne(yi) Bilmektir?
}

\author{
Selim TIRYAKİOL*
}

\section{$\ddot{O} \mathbf{z}$}

Bu çalışma dil öğrenirken ya da öğretirken beyinde ne tür bir bilgi işlendiğini inceleyerek dil eğitimindeki mevcut uygulamalara teklifler getirmektedir. Dil eğitimindeki yaklaşımların arka planında insan beynine ilişkin keşifler büyük rol oynamaktadır. O hâlde "Dil bilmek ne tür bir bilgiyi bilmektir?” sorusu dil eğitimini daha iyi anlayabilmemizi sağlayacak önemli bir sorudur. Çocukların ana dilini bilmesi ile çocukların ya da yetişkinlerin ikinci bir dil bilmeleri arasında bir fark olduğu görülmektedir. Bilinçsiz bir öğrenme süreci ana dili için yeterli olurken, ikinci dil için yeterli olmamaktadır. İnsan beyniyle ilgili yapılan çalışmalar insan belleğini işlenen bilginin türü bakımından açık ve örtük olarak ikiye ayırmaktadır. Bellek ve öğrenme üzerine yapılan araştırmalar açık bilginin örtük bilgiye dönüştürülüp dönüştürülemeyeceğine odaklanmıştır. Bu dönüşüm bir gereklilik olarak görülmektedir; çünkü insan beyni örtük bilgiye daha kolay ulaşabilmekte ve iletişim esnasında bu tür bilgiyi pratik olarak kullanmaktadır. Bu yönüyle gerçek dil bilgisi örtük bir bilgidir. Nihai olarak bu çalışma dört farklı sonuca varmaktadır: (1) Başarılı bir dil eğitimi için dil öğretiminde planlanan süreçlerle kişinin dil edinim süreci örtüşmelidir. (2) Öğretmenler dil derslerine içeriği inceleme konusu olabilecek tarih, coğrafya gibi derslerden farklı yaklaşmalıdır. Bu yönüyle öğretmen yetiştiren programlar dersleri arasına öğrencilerin hem birden fazla dille Türkçeyi karşılaştırabilecekleri hem de soyut olarak dilin ne olduğu ile ilgili formasyon kazanabilecekleri dersler koymalıdır. (3) Dil eğitiminde kullanılan ders kitapları (ya da ders programları) açık öğrenmenin örtük öğrenmeye dönüştürülebileceği görüşüne dayanmaktadır. Ancak bu kitaplar bu çalışmada da gösterilen girdi ve çıktı sürecini başarılı bir şekilde uygulayabildikleri sürece etkili olabilir. Aksi takdirde ders kitaplarının dil gelişimine gerçek bir etkisi görülmemektedir. (4) Dil yetkinliğini ölçmek için ölçme aracının örtük türdeki bilgiye odaklanması gerekmektedir. Açık bilgiyi ölçmek öğrencilerin dili gerçekten bildiği anlamına gelmemektedir.

Anahtar Kelimeler: Bellek, Açık, Örtük, Bilgi, Öğrenme, Edinme.

\footnotetext{
* Dr. Öğr. Ü., İstanbul Medeniyet Üniversitesi, Eğitim Bilimleri Fakültesi, İstanbul, Türkiye. Elmek: selim.tiryakiol@medeniyet.edu.tr https://orcid.org/0000-0001-5735-2320.
} 


\title{
The Classification of Memory and Its Effects on Language Education What Type of Knowledge is Language Knowledge?
}

\begin{abstract}
This study investigates the type of knowledge that is processed in the brain while learning or teaching a language, as well as raises proposals for current practices in language education. Discoveries about the human brain have a key role in defining approaches to language education. Thus, the question of "what kind of knowledge is language knowledge?" is an important one for understanding language education. There is a difference between knowledge of a native language by children and knowledge of a second language by children or adults. Although unconscious forms of learning are sufficient for acquiring first languages, this is not the case for second language. The memory is divided into two subtypes: explicit and implicit. The literature on memory often focuses on whether explicit knowledge can be converted into implicit knowledge. This conversion process is a beneficial requisition because the human brain can access implicit knowledge more easily, making it more practical for use during the natural flow of communication. In that sense, true language knowledge is implicit. Finally, this study has four conclusions: (1) Language education curriculums and language acquisition should be overlapping. (2) In language classes, the content cannot be a subject of investigation. Thus, educators must approach language classes differently than other subjects such as history or geography. In that way, teacher training programs should include classes which contrast Turkish with other languages and reflect on what language is in the abstract sense. (3) The coursebooks (or language curriculums) depend on the idea that explicit knowledge can be converted into implicit knowledge. But these books can only be effective as long as they can run the input and output circle successfully. (4) Assessment tools should focus on the implicit type of knowledge, since assessing explicit knowledge does not mean that students genuinely know the language.
\end{abstract}

Keywords: Memory, Explicit, Implicit, Knowledge, Learning, Acquisition. 


\section{Extended Summary}

Language education, as any other scientific discipline, employs a number of approaches, methods, and strategies. These approaches should be considered on a continuum rather than sharply separated categories. Many approaches to language teaching that are incompatible in some ways coexist and can be used at the same time (N. Ellis, 2008). Once language education is considered as a continuum, there are the views on one end that argue that language is acquired totally naturally, and perspectives on the other end that language can be taught in an explicit form (MacWhinney, 1997). All these arguments stem from researchers' perceptions of how language knowledge is encoded in the brain. For this reason, "what type of knowledge is language knowledge?" is a critical question for understanding language and language education. Thus, this study aims to clarify what kind of knowledge we deal with while learning or teaching language and reviews different approaches in language education practices from the perspective of how knowledge is processed in the brain.

In addition to the question raised in the previous paragraph, a comparison of $\mathrm{L} 1$ and L2 acquisition reveals that there is a fundamental difference between L1 and (adult) L2 knowledge. While the unconscious and implicit learning mechanism is adequate for acquiring L1, it is insufficient for reaching L2 in adulthood. Studies of the brain and memory demonstrate that humans have two types of memory: explicit and implicit. As a result of the existence of different memory types, people can do what they learn implicitly but may not be able to explain it, while they may be able to explain what they learn explicitly but not necessarily do it. Research on implicit and explicit learning types in language education has focused on whether these two types of learning can be transformed into each other. At this point, a critical goal for the language teaching profession is transforming explicitly-learned knowledge into implicit knowledge, or focusing on learning a language solely implicitly since fluency in a language is only possible with implicit knowledge. The reason for this is that the human brain can access implicit knowledge more directly for use in communication. On the contrary, since explicit knowledge does not involve directly knowing the language, but only knowing about the language, accessing such 
knowledge in the brain is a slower process (N. Ellis, 2005; R. Ellis, 2005; Schmidt, 1990). Thus, there are two main views in the literature regarding how humans can acquire a language.

The first is that explicit and implicit learning are not in interaction. Thus, a language can only be learned implicitly. This view stresses the concept of acquisition rather than learning. One can claim that (1) language must be learned implicitly, (2) learning that confers explicit knowledge cannot be converted into acquisition that confers implicit knowledge, and (3) conscious learning can only be used to monitor output in language (Krashen and Terrell, 1998).

The second view is that explicit and implicit learning are in interaction. This view claims that explicit knowledge can be converted into implicit knowledge, and that is not sufficient to be exposed to a language in order to learn it. Language knowledge can be made implicit by learning it explicitly following a particular curriculum (N. Ellis, 2011). This view is distinct from the first view in the sense that implicit learning is characterized by gradual accumulation of associations between frequently co-occurring features, rather than unconscious induction of abstract rule systems (Schmidt, 1990).

Finally, this study has four conclusions: (1) Language education curriculums and students' language acquisition process should be overlapping in order to conduct successful language education. (2) In language classes, the content cannot be a subject of investigation. Thus, educators must approach language classes differently than other subjects such as history or geography. In that way, language teacher training programs should include classes for pre-service teachers which contrast Turkish with other languages and reflect on what language is in the abstract sense. (3) Language teaching sets (or language curriculums) for students which have been used in language education depend on the idea that explicit knowledge can be converted into implicit knowledge. But these sets can only be effective as long as they can run the input and output circle (figure 1) successfully. Otherwise, the language teaching sets cannot make a true contribution to language development. (4) Assessment tools in language education should focus on the implicit type of knowledge to assess language competence, since assessing explicit knowledge does not mean that students genuinely know the language. 


\section{Giriş}

Dil eğitimi, her bilimsel disiplinde olduğu gibi farklı yaklaşımları, metotları ve teknikleri içinde barındırmaktadır. Yaklaşımlar birbirlerine etki ya da tepki yoluyla ortaya çıktıkları için çoğunlukla ayrılan yönleri ön plana çıkmaktadır. Ancak dil öğretimi çalışmalarında yaklaşımlar uygulamada kendinden öncekileri yok etmiş yenilikler olarak değil, bir süreklilik olarak okunmalıdır. Böylece birbiriyle belirli noktalarda çelişen birçok dil öğretim yaklaşımı hâlâ birlikte varlığını sürdürmektedir (N. Ellis, 2008: 10).

1960 ve 1970'lere kadar yaygın olan gramer-çeviri ve bilişsel kodlama gibi metotlar dili formların işlenmesine dayalı bir beceri olarak görmüşler ve dil öğrenenlerin dili formlara ve bunların kurallarına dayalı bir şekilde öğrenmeleri gerektiğini düşünmüşlerdir. Bundan dolayı dilde yapılara, çekimlere ve kurallara yoğunlaşmışlardır. $\mathrm{Bu}$ bakış açısı dilin kuralları öğrenildiğinde kullanımının da arkasından geleceğini varsaymıştır. İkinci Dünya Savaşı sırasında meşhur olan işitmeye dayalı metot ve ardından gelen "Doğal" ve "ỉletişim"e dayalı yaklaşımlar ise yetişkinlerin dil ediniminin çocukların dil edinimi sürecine benzediğini varsaymıştır. Dilin bir bilgiden çok beceri olduğunu varsayarak öğretim sürecinde gramere açık bir şekilde yer vermemişlerdir (N. Ellis 2011: 35-36). Nörobilim, psikoloji, bilişsel dilbilim gibi alanlarda meydana gelen yeni keşifler ve ortaya çıkan yeni yaklaşımlar dil edinimi çalışmalarında da yaklaşımların sürekli olarak güncellenmesine sebep olmaktadır. Dil öğretimi yaklaşımlarını bir doğru üzerinde düşündüğümüzde bu doğrunun bir ucunda tamamen doğal olarak dilin edinileceğini savunan görüşler yer alırken öbür ucunda dilin programlı ve açı bir öğretim yoluyla öğrenilebileceğini savunan görüşler yer almaktadır (MacWhinney, 1997: 277); ancak dil öğretimi sadece bu iki uçtan ibaret değildir. Bu iki uç arasında yer alan uygulamaların olduğu gerek teoride gerek sınıflar gözlemlendiğinde görülmektedir.

Bütün bu tartı̧̧malar aslında dilin zihinde nasıl bir bilgi olarak temsil edildiği ile ilgilidir. Bütün yaklaşımların arka planında aslında beynimize, özellikle de bellek yapımıza ilişkin keşifler büyük rol oynamaktadır. O hâlde "Dil bilmek ne tür bir bilgiyi bilmektir?" sorusu genelde dili özelde dil eğitimini daha iyi anlayabilmemizi 
sağlayacak önemli bir sorudur. Öğretim ve öğrenme açısından düşünüldüğünde soru şöyle de değiştirilebilir: "Dil öğrenirken/öğretirken ne tür bir bilgi öğrenmekteyiz/ öğretmekteyiz?”. Bu çalışma dil öğrenirken ya da öğretirken ne tür bir bilgi ile meşgul olduğumuzu literatüre dayalı olarak ortaya koymayı ve bu bilginin dil eğitiminde ortaya çıkardığı farklı yaklaşımları uygulamalara olan yansımaları açısından değerlendirmeyi amaçlamaktadır.

\section{2. Çocukların ve Yetişkinlerin Dil Gelişimi Arasındaki Farklar}

Beynimizdeki dil bilgisinin ${ }^{1}$ nasıl bir bilgi olduğu çocukların ve yetişkinlerin dil gelişimi karşılaştırıldığında daha iyi anlaşılmaktadır.

Çocuklar dili bilinçli ve açık değil, etrafındaki konuşmalardan bilinçsiz ve örtük olarak kazanmaktadır². Hiçbir ebeveyn çocuğunu karşısına alıp ona birtakım yapıları ve bunların kurallarını öğretmeyi düşünmemektedir. Çocuklar dildeki belirli yapılara ve onların anlamlarına dikkat kesilerek dili kazanmazlar (N. Ellis, 2011: 35; Krashen ve Terrell, 1998: 26-27). Bununla birlikte araştırmalar (Littlemore, 2009: 181; Krashen ve Terrell, 1998: 35) çocukların dil ediniminin yetişkinlerin dil öğrenirken maruz kaldıklarından farklı özellikler taşıdığını not düşmektedir. Çocukların maruz kaldığı dil daha vurgulu, daha basitleştirilmiş ve tekrarlıdır. Belirli yapılar abartılı şekilde seslendirilir. Etraftaki kişiler çocuklarla konuşurken farkında olmasalar da pedagojik bir yaklaşım sergilerler. Aynı zamanda çocuklar niyet okuma (intention-reading) ve örüntü bulma (pattern finding) becerilerini bu süreçte oldukça iyi kullanırlar.

Çocuk bir dil edindikten ${ }^{3}$ (D1) ve kritik periyodu geçtikten sonra yetişkinliğe

\footnotetext{
1 Bu noktada dil bilgisi öbeği, Türkçede gramerin karşıllı̆̆ olarak kullanılan dilbilgisi değil dilin beyinde temsil edildiği bilgi anlamında kullanılmaktadır. Bu sebeple 'gramer' terimini Türkçeye 'dilbilgisi' diye çevirmenin beyinde temsil edilen 'dil' bilgisi ile karışıklığa yol açtığı için yanlış bir tercih olduğu da görülmektedir. Bazı araştırmalar dilin bilgisini ifade etmek için 'dil bilgisi' (ayrı yazıldığında), grameri ifade etmek için 'dilbilgisi' (birleşik yazıldığında) kullanımını tercih etseler de bu da 'dilin gramer bilgisi' ifadesi 'dilin dilbilgisi bilgisi' gibi bir tamlama ortaya çıkaracağı için kulağa tuhaf gelmektedir. Neticede bir dil gramerinden ibaret değildir, onun bilgisi de gramer bilgisinden ibaret değildir.

$2 \mathrm{Bu}$ cümlede geçen açık ve örtük kavramları bu makalenin ana fikrini oluşturmaktadır. Açık (explicit) kavramı bilinçli ve niyetli bir şekilde, dikkati de devreye sokarak bir konunun öğrenilmesini ifade ederken örtük (implicit) kavramı niyet olmadan, bilinçaltında, dikkati devreye sokmadan bir konunun öğrenilmesini ifade etmektedir.

3 Literatürde temelde edinim ve öğrenme arasında ayrım yapılarak edinimin D1 kazanımını, öğrenmenin ise D2 kazanımını ifade ettiği belirtilmektedir. Süreci karakterize etmek için bu ayrım oldukça faydalıdır; ancak edinimin D1 kazanımını ifade ettiği ve D1'de bilinçliliği ve açıklığı ifade eden öğrenme sürecinin oldukça sınırlı olduğu görülse de D2'nin yalnızca bilinçli ve açık öğrenmeden oluştuğu da iddia edilememektedir. D2'de kişi, aynı anda hem açık bir öğrenme süreci hem de örtük bir edinim süreci yaşayabilmektedir. Hatta bazen yalnızca örtük bir edinim süreci de yaşanabilmektedir. Bu yüzden bu çalışmada edinim ve öğrenim ayrımı gerekli olduğu yerlerde vurgulanmakla birlikte her ikisini birlikte ifade etmek gerektiğinde 'kazanım' terimi de kullanılmışıır; ancak çalışmanın ilerleyen sayfalarında açık ve örtük öğrenme arasındaki ayrım vurgulanmıştır.
} 
doğru ilerledikçe iki ya da daha fazla dil öğrenmek istediğinde (D2 ${ }^{4}$ ) durum D1 ediniminden farklılık göstermektedir. Yetişkin kişiler her ne kadar tamamen hayatın içinde, tabii olarak dile maruz kalsa da çocuklara benzer bir yetkinlik gösterememektedir (Littlemore 2009). Yetişkinler çocuğun maruz kaldığı gibi çocuğa yönelik pedagojik dile maruz kalmamaktadır. Yetişkinlerin maruz kaldığı dil daha katıksız, çocuklarınkinden daha otantik ve doğrudandır. Bu yüzden bazı araştırmalar (N. Ellis 2011: 35; Littlemore 2009: 181; R. Ellis, 2005: 217) yetişkinlerin herhangi bir girdi yardımı (modifikasyonu) olmadan tıpkı çocuklar gibi dili edinmesini beklemeyi gerçekçi görmemektedir. Yetişkinlerin dil öğrenmek için çoğu zaman ek bir desteğe, dikkate ve bilinçli bir öğrenmeye ihtiyaç duyduklarını belirtmektedir.

D1 ve D2 kazanımı arasında yapılan bu karşılaştırma D1 ve (yetişkin ${ }^{5}$ ) D2 bilme arasında bilginin mahiyeti açısından bir fark olduğunu göstermektedir. Bilinçsiz ve örtük öğrenme süreci D1 edinimi için yeterli olurken yetişkinlerde D2 için neden yeterli olmamaktadır? Bu sorgulama birkaç on yıldır psikodilbilimcileri, bilişsel psikologları ve nörobilimcileri meşgul etmiştir (Sanz ve Leow, 2011: 1).

\section{Bilgi ve Bellek Türleri}

Beyinle ilgili yapılan çalışmalar insanda örtük ve açık olmak üzere iki türlü bellek olduğunu ortaya koymuştur ${ }^{6}$ (Bkz. Bialystok, 2011; Lenet vd. 2011; N. Ellis, 2005; Schmidt 1990). İnsan beynine dair yaşanan bu keşifler dil edinimi çalışmalarına da hem teorik hem de metodolojik yönden etki etmiştir.

Bir dil birimini (kelime, ek vs.) öğrenirken beynimiz belirli süreçlerden geçmektedir. İşleyen belleğimizi içeren beynin ön lobu dikkatle seçme, algılayarak dâhil etme, bilinçli eylemleri bir araya getirme gibi işlevler görmektedir. Dildeki birimler bu süreçlerden geçerek beyinde fark edilmektedir. Ardından hipokamp (hippocampus) adı verilen beyindeki beyaz çıkıntı önceden fark edilmiş olanları bağlayarak bütüncül (epizodik) tasarımlara dönüştürmektedir (N. Ellis, 2011: 43).

Bir kaza sonucu beyin hasarı yaşamış olan hastanın hikâyesi insan belleğine dair

4 D2, ikinci dil ifadesinin kısaltması olarak kullanılmaktadır. İki ya da daha fazla dil bilmeyi ifade etmektedir. D1 ise bir insanın ilk dilini yani ana dilinin kısaltmasıdır.

5 Bebeklikte D2 edinme ile kritik periyod geçildikten sonra D2 öğrenme birbirine karıştırılmamalıdır. Burada yetişkin kelimesinin vurgulanması bu sebepledir. Literatürde D2 edinmenin farklı türleri tartışılmakla birlikte bu çalışmanın kapsamına girmediğinden burada bu notu düşmekle yetineceğiz.

6 Bellek, araştırmalarda gelen bilginin 'türüne' ve 'işlenme tarzına' göre tasnif edilmektedir. Örtük ve açık bellek gelen bilginin türüne göre belleği tasnif etme yaklaşımının bir sonucudur. Gelen bilginin işlenme tarzına göre ise bellek kısa süreli ve uzun süreli olarak tasnif edilmektedir. Açık bellek tanımlanamayan örtük bellek ise tanımlanabilir bellek olarak da anılmaktadır (Onan, 2011: 94). 
bilim adamlarına önemli ipuçları vermiştir. Hasta, doktoru ile tokalaşırken doktorun kasıtlı olarak elinde tuttuğu iğne hastanın eline batmıştır. Aynı hasta doktoru ile bir sonraki görüşmesinde bir önceki olayın etkisi ile onun elini sıkmayı reddetmiştir. Fakat aynı zamanda daha önce doktorunu hiç görmediğini ifade etmiştir. $\mathrm{Bu}$ vaka beyin hasarı yaşamış olan bu hastanın kendisine acı veren bir hadiseyi bilinçaltında örtük olarak tutabildiğini; ancak yeni tanıştığı bir insanı hafızasında tutamadığını göstermektedir. $\mathrm{Bu}$ tür hastaların daha önce yaşadığı bir hadiseyi bilinçli olarak hatırlamasını gerektiren yeni açık bellekleri sürdüremedikleri görülmektedir. Bununla birlikte bu tür hastalar daha önce yaşadığ 1 bir hadiseyi ya da maruz kaldığı uyaranı bilinçli olarak hatırlamasını gerektirmeyen fakat bilinçaltında depolanan örtük belleği devam ettirdikleri anlaşılmıştır (N. Ellis, 2011: 37).

Yine bu tür beyin hasarlı hastalar üzerinden yürütülen çalışmalar örtük ve açık belleklerin beyinde farklı alanlarda işlendiğini göstermiştir. Açık bellek beynin ön lobundaki sinir sistemleri tarafından işlenmektedir. Öbür yandan örtük bellek duyusal ve motor kortekslerde işlenmektedir. Örtük ve açık bilgi türleri beynin farklı alanlarında depolansa da bu ikisinin arasındaki ilişkinin mahiyeti dil ediniminde tartışmalara ve farklı yaklaşımlara yol açmıştır (N. Ellis, 2008; 2011; Bialystok, 2011).

\section{4. Örtük/Açık Öğrenme ve Aralarındaki İlişki}

Örtük ve açık bellek kavramları örtük ve açık öğrenme kavramlarını ortaya çıkarmıştır. Çocukların dili büyük ölçüde bilinçsiz olarak kazandıkları yukarıdaki paragraflarda vurgulanmıştı. Okuma yazma öğrenme dönemindeki bir çocuğa "Türkçede çokluk nasıl yapılır?" diye bir soru sorulsa muhtemelen "Bilmiyorum." cevabını verecektir; fakat soru şöyle düzenlenirse "Bu elimde bir kalem var, şu elimde de başka bir kalem var, o hâlde kaç kalemim var?” sorusuna muhtemelen vereceği cevap "iki kalem” olacaktır. Üç ve daha fazla kalem için gelecek cevap ise "üç kalem" ya da "kalemler" olacaktır. Bu örnek, çocuğun aslında dili ve onun gramerini bilinçaltında örtük olarak bildiğini göstermektedir. Ana dili eğitiminde gramer öğretimi söz konusu olduğunda bu perspektifle düşünülmelidir (Bk. R. Ellis, 2006). Ana dili olarak Türkçe derslerinde öğretmenlerin zihninde şu sorunun her zaman yer etmesi faydalı olacaktır: Yukarıdaki örnekte olduğu gibi grameri bilen bir çocuğa gramer eğitimi nasıl yapılmalıdır?

Öbür yandan bilinçli bir öğrenme sonucunda dil öğrenmiş olan bir yetişkini düşündüğümüzde ona da aynı şekilde “Türkçede çokluk nasıl yapılır?” diye 
sorulduğunda çokluk ekini dilin diğer yapılarından yapı ve anlam bakımından ayırt edebilme ve izah edebilme ihtimali vardır. Bir yetişkin dilin yapıları ile ilgili hiçbir şey izah edemese bile kelimede bulunan "+1Ar” ekine dikkat çekebilir. Dil eğitimi almışsa bunu daha ayrıntılı bir şekilde analiz de edebilir. Bu iki örnek bir işi yapabilmekle o işle ilgili bilgiyi karşımızdakine aktarabilmek arasında beynimizdeki işlev mekanizması bakımından kesin bir ayrım olduğunu göstermektedir. Bir anlamda örtük olarak öğrendiklerimizi yapabilir ama açıklayamayabiliriz. Açık olarak öğrendiklerimizi yapsak da yapamasak da açıklayabiliriz (Leow, Johnson ve Zarate-Sandez, 2011: 63).

Reber (2011) bu iki öğrenme türü arasındaki ayrımı yapay bir gramerden üretilen harf dizilerini öğrenen insanlar üzerinden ortaya koymuştur. Bu kişiler MXRMXT, VMTRRR gibi dizilerden oluşan harfleri daha sonra hatırlamak için çalışmışlardır. Daha sonra bu kişilere uygulanan testlerde tıpkı çocuklara sorulan kalem testinde olduğu gibi bu tür dizilerde yatan düzeni öğrendikleri; fakat gerekçelendiremedikleri görülmüştür. Buna göre örtük öğrenme karmaşık bir uyaranın altında yatan düzeni doğal, basit ve bilinçli bir işlem olmadan edinmektir. Açık öğrenme ise kişinin bir uyaranın belirli bir görünüşüne dikkat kesildiği ve kasıtlı olarak zihnindeki hipotezleri test ettiği bilinçli bir süreçtir. Her ne kadar birbirinden farklı öğrenme süreçleri olsa da bu iki tür arasındaki ilişki uzun yıllardır araştırmacıları meşgul etmektedir.

Dil eğitiminde örtük ve açık öğrenme türleri üzerine yapılan araştırmalar bu iki tür öğrenmenin birbirine dönüştürülüp dönüştürülemeyeceğine odaklanmıştır. Bu noktada dil öğretimi açısından asıl önemli nokta; açık olarak öğrenilen bilginin örtük bir bilgi hâline dönüştürülmesidir ya da kişinin dili doğrudan örtük olarak öğrenmesidir; çünkü dilde akıcılık ancak örtük bilgi ile mümkündür. Bunun nedeni insan beyninin depoladığg örtük bilgiye daha hızlı bir şekilde ulaşabilmesi ve iletişimde kullanabilmesidir. Bunun tersine açık bilgi doğrudan doğruya dili bilmek değil, dil hakkında bilmek demek olduğu için beyinde bu tür bir bilgiye ulaşmak daha yavaş olmaktadır. Açık bilgi ${ }^{7}$ dili bir nesne gibi inceleyerek elde edilen bilgidir. $\mathrm{Bu}$ durum da akıcılığı yavaşlatmaktadır (N. Ellis, 2005; R. Ellis, 2005; Schmidt, 1990).

İnsanın dili -akıcı kullanacak şekilde- nasıl öğrenebileceği ile ilgili literatürde iki temel görüş öne çıkmaktadır. Bunlardan ilki "Açık ve örtük öğrenme etkileşimsizdir"."

7 R. Ellis (2005: 211) bu durumu dilde anlam üzerinden açıklamaktadır. Buna göre dilde iki türlü anlam vardır. Birincisi semantik anlam, ikincisi ise pragmatik anlamdır. Dil öğrenirken anlama odaklanmak gerekmektedir; ancak burada asıl vurgulanan pragmatik anlamdır. Çünkü dil öğrenirken semantik anlama odaklananlar dile bir nesne gibi yaklaşırlar ve onu bir nesneyi inceler gibi incelerler. Oysa pragmatik anlama odaklananlar dili iletişim için bir araç olarak görürler ve onunla iletişim kurarlar.

8 Bu terim İngilizce literatürde non-interface olarak oturmuş olan kavramın bizim tarafımızdan Türkçeleştirilmiş şeklidir. 
görüşüdür. Açık ve örtük öğrenme etkileşimsiz ise ve dili gerçek anlamda öğrenmek örtük öğrenmek anlamına geliyorsa dil tamamen ve sadece örtük olarak öğrenilmelidir. $\mathrm{Bu}$ görüş temelde örtük ve açık belleğin beyinde farklı alanlarda işlendiğini ortaya çıkarmış olan nörobilim araştırmalarına dayanmaktadır (Paradis, 1994’ten aktaran R. Ellis, 2005: 215).

İkincisi ise “Açık ve örtük öğrenme etkileşimlidir.” görüşüdür. Bu görüş ilk görüşün tam aksine, örtük ve açık öğrenmenin birbiriyle yakından ilişkili olduğunu, kişinin dili iletişim amacıyla kullandıkça dil bilgisinin açık bilgiden örtük bilgiye dönüşeceğini savunmaktadır. Açık bilginin örtük bilgiye dönüştürülebileceği bir kez kabul edildikten sonra bu görüş, birinci görüşün aksine dilin yalnızca örtük olarak öğrenilmesi gerekmediğini, ders anlatımı ya da bilinçli ve programlı bir şekilde çalışarak dilin öğrenilebileceğini savunmaktadır (Bk. Schmidt, 1994'ten aktaran R. Ellis, 2005: 215).

Araştırmacılar ve öğreticiler tarafından temelde birbirine zıt gibi duran bu iki görüş benimsenmiş olmakla birlikte bu görüşler arasında bu görüşlere farklı derecelerde yakınlaşan ya da uzaklaşan uygulamalar da mevcuttur. Aşağıda bu iki görüş tartışılmaktadır.

\section{Açık ve Örtük Öğrenme Etkileşimsizdir.}

Bu bakış, açık ve örtük öğrenme arasında bir etkileşim olmadığını, dilin yalnızca örtük olarak öğrenilebileceğini savunmaktadır. Buna göre dil öğrenme çizgisel bir şekilde ilerleyen, bu nedenle bütün ayrıntılarıyla programlanabilecek tek boyutlu bir süreç değildir (Bialystok, 2011: 49). Dil maruz kalınan girdiler yoluyla zamanla bilinçaltında birikme yoluyla 'edinilmekte'dir. Bu görüş öğrenim kavramına karşılık edinim kavramını vurgulamaktadır. Öğrenme bu çalışmada işlenen açık bilgiye işaret ederken; edinim örtük bilgiye işaret etmektedir. Bu görüşün öncülerinden sayılabilecek Krashen ve Terrell (1998) bu görüşün ana fikirlerini şöyle özetlemiştir: 1. D2'de bir ürün ortaya koyabilmek için dil örtük olarak öğrenilmelidir. 2. Açıklığı ifade eden öğrenme, örtüklüğü ifade eden edinime dönüştürülemez. 3. Bilinçli öğrenme yalnızca ortaya konulan çıktı üzerinden denetleyici/editör olarak kullanılabilir.

Literatürde bu görüşün ana fikirlerini destekleyecek kanıtlar da sergilenmiştir. Örneğin çocuklarda D2 olarak İngilizcenin gelişimini araştıran çalışmalar, farklı D1'e sahip olan çocukların (Çince ve İspanyolca) İngilizcede ‘aynı’ yapılarda zorlandıklarını

Interface iki şeyin birbiriyle buluştuğu ve etkileşime girdiği ortak noktaları ifade eder. Bunu matematik derslerinde öğrendiğimiz kümeler konusuna da benzetebiliriz. 
ortaya koymuşlardır (Krashen ve Terrell, 1998: 28-29). Bu durum dilin zihinde evrensel bir edinim sırasına sahip olduğunu ve bunun öğretim yoluyla değiştirilemeyeceğine işaret etmektedir. Benzer şekilde VanPatten (2011: 9-12) dilin sentaksının öğretim yoluyla öğrenilmesinin mümkün olmadığını vurgulamaktadır. Ona göre sentaksın zihindeki evrensel gramer tarafından belirlenmiş olan bir ajandası vardır. Yani evrensel gramer tarafindan belirlenmiş ve yürütülen gelişim aşamalarına müdahale etmek, onları öğretim yoluyla değiştirmeye çalışmak işe yarar bir yöntem değildir. Sentaks kişinin farkındalığı dışında, bilinçaltında, dilde girdilere maruz kaldıkça, birikim yoluyla gelişmektedir. Günlük hayatta gözlemlediğimiz bazı durumlar da bu varsayımları desteklemektedir. Yetişkinlerin D2 gelişimleri gözlemlendiğinde açık öğretim yoluyla belirli bir seviyeye kadar gelseler de açık olarak öğrendikleri bilgiyi gerçek hayatta kullanamadıkları, dili kullansalar da belirli bir noktadan sonra ileriye gidemedikleri ya da çok yavaş ilerledikleri görülür (Bialystok, 2011: 49). Sınıflarda dil öğretimi sırasında öğretmenler bazı konuların üzerinde ne kadar dururlarsa dursunlar, öğrenci konuşmaya ve yazmaya gelince verilen dönütlerin işe yaramadığı görülür. Bu durum dil ediniminin evrensel bir sıralaması olduğuna ve bir aşama geçilmeden diğer aşamanın edinilmesinin öğretim yoluyla da olsa zor olduğuna işaret etmektedir. Bu noktada Krashen ve Terrell (1998: 33) dilde yetkinliğin yeteri kadar okuma ve dinleme yapıldıkça kendiliğinden ortaya çıkacağını iddia etmektedir.

$\mathrm{Bu}$ görüş dilin tamamen örtük olarak öğrenilebileceğini savunsa bile bilinçli ve açık öğrenmeye de bir yer vermek durumunda kalmıştır. Buna göre dil öğrenen kişinin açık bilgileri, ortaya koyduğu çıktıları denetlemek/editörlük yapmak vazifesini görmektedir. Buna göre kişi D2'de çıktı ürettikçe kendi ortaya koyduğu ürünle daha önceden ana dili normlarına göre zihninde oluşturduğu grameri karşılaştırmaktadır. Bir anlamda kişi konuşur ya da yazarken sürekli olarak bir denetim mekanizmasını çalıştırmaktadır. Bu denetim mekanizması sayesinde kendi ortaya koyduğu ile olması gereken arasındaki farka dikkat kesilmekte, sonraki cümlelerinde önceden fark ettiği bu farkları doldurarak ilerlemektedir. Günlük hayatta konuşurken ve yazarken bir problem olduğunu hissedip kişinin cümlesini yeniden düzenleyerek ne demek istediğini daha açık ifade etmeye çalışması buna bir örnektir.

Krashen ve Terrell (1998: 19, 57) açık bilginin bir denetim mekanizması olarak işlev gördüğünü ifade etse de bu mekanizmanın sınırlılıklarına da dikkat çekmiştir. İlk olarak bu denetim mekanizmasını dildeki basit kurallar için işletmek kolaydır. Ancak zor kuralları denetlemek ve düzeltmek daha zordur. Türkçede örneğin 
çokluk eki ile ilgili bir yanlış hemen düzeltilebilir; ancak -mAk isim-fiil eki ile ilgili bir standart dışı kullanımı fark etmek ve düzeltmek daha zordur. Ayrıca bu denetim mekanizmasının çalışması için belirli şartların yerine gelmiş olması gerekir. 1. D2 kullanıcısı ürettiği çıktıyı kontrol etmek için yeteri kadar vakti olmalıdır. 2. Konuşan kişi çıktının doğruluğuna odaklanmış olmalıdır. 3. Kuralı bilmelidir. Doğal bir sohbet esnasında bütün bunlar nadiren karşılanır. Sohbetler genelde çok hızlıdır. Konuşan kişinin dikkati nasıl söylediğinde değil ne söylediğindedir. Buna göre bilinçli gramer bilgimiz dil bilgimizin çok küçük bir kısmını oluşturmaktadır. Yukarıda bahsi geçen bütün şartlar yalnızca geleneksel gramer testlerinde sağlanmaktadır. $\mathrm{Bu}$ testler ise sözlü değil, yazılıdır. Öğrencileri dilin mesajı üzerine değil, formları üzerine düşündürmek için tasarlanmıştır.

\section{Açık ve Örtük Öğrenme Etkileşimlidir.}

$\mathrm{Bu}$ görüşü benimseyenler açık ve örtük öğrenmenin etkileşim içerisinde olduğunu ve açık bilginin çeşitli metotlarla örtük bilgiye dönüştürülebileceğini savunmaktadır. Bu görüşe göre dilde yalnızca girdiye maruz kalmak yeterli değildir. Dil belirli bir program takip edilerek açık bir şekilde öğrenilip pratikler yoluyla örtük bilgi hâline getirilebilir. Bu tür bir öğrenme doping etkisi yaparak dilin daha hızlı öğrenilmesini sağlamaktadır (N. Ellis, 2011). Bu bakış açısı örtük öğrenmenin soyut kural sistemleri üzerinden bilinçsiz bir çıkarım yoluyla değil, sürekli olarak tekrar ederek otomatikleşme yoluyla gerçekleştiğini iddia ederek birinci bakış açısından ayrilmaktadır (Schmidt, 1990).

Bu noktada farklı bir duruş göze çarpmaktadır. N. Ellis (2005: 307) Krashen’ın öğrenme ve edinim ayrımına atıfta bulunarak, Krashen'ın açık bilgiyi ifade eden öğrenmenin örtük bilgiyi ifade eden edinime dönüştürülemeyeceği iddiasının doğru olduğunu; ancak bu iki bilgi türü arasında etkileşim bulunduğunu belirtmektedir. Bu yönüyle N. Ellis iki bilgi türü arasında dönüşümün olmadığı hipotezini kabul etse de etkileşimlilik tarafında yer almaktadır.

Bu görüş literatürde 'bilinç' ve 'dikkat' kavramlarıyla birlikte tartışılmıştır. Buna göre insanın bir şeyi öğrenmesi için öncelikle ona bilincini yöneltmesi, dikkat kesilmesi gerekir. Dikkat öğrenmeye yönelik atılan ilk adımdır. Dikkat beyindeki öğrenme lobları ile öğrenilecek materyal arasında arayüz işlevi görür (N. Ellis, 2011: 42, 45). Dili kullanamamamızın sebebi onun kurallarını anlamamamız değil, her bir birime yeteri kadar dikkat kesilmememiz ve -farkında olmasak da- iletişim esnasında bazı birimleri gözden çıkarmamızdır. Dildeki birimlere yeteri kadar dikkat 
kesilemememizin sebebi insanın o andaki psikolojik ve bilişsel durumu olabileceği gibi ilgili birimlerin belirginliği ve sıklığ 1 da etkilidir. Bazı birimlerin iletişim bakımından gereksiz olması onları gözden çıkarmamıza sebep olmaktadır. Özellikle gramatik ve fonksiyonel yapılar, anlamlı yapılardan daha zor fark edilmekte ve öğrenilmektedir. Bunun için aşağıdaki örneği ele alalım.

(1) Ömer dün yürüdü.

Türkçeden verilen bu örnekte eylemin zamanını belirten gramatik birim (-DI) D2 öğrencileri tarafından bir müddet diğer zaman ekleriyle karıştırılabilir. Bazen bu durum çocukların dil gelişiminde de görülmektedir. Kişi yapıyı öğrense bile bir süre daha şöyle cümleler kurabilir.

(2) Ömer dün yürür.

(3) Ömer dün yürüyor.

Bunun sebebi kişinin zaman ifadesini "dün” anlamlı yapısı üzerinden zaten çıkarabilmesi ve (2) ve (3) numaralı cümleleri kurduğunda iletişim bakımından büyük bir problem ortaya çıkmamasıdır. Buna göre iletişim bakımından çok önem taşıyan yapılar daha kolay öğrenilebilirken az önem taşıyan yapılar öğrenen tarafından gözden çıkarılabilmektedir. Bu yüzden bilinçli bir dikkate dayanan açık öğretim pratik bakımdan bir ihtiyaçtır. Ancak bu noktada açık öğretimde nasıl bir yol izleneceği önem kazanmaktadır.

Açık öğretim doğrudan gramer anlatımı yoluyla yapılmak zorunda değildir. Bunun için literatürde girdi, alındı ve çıktı gibi kavramlar kullanılarak süreç tarif edilmektedir.

Şekil 1 Dil Girdisi ve Çıktısı Süreci (Krashen ve Terrell, 1998; VanPatten ve Cadierno, 1993; Leow, Johnson ve Zarate-Sandez, 2011: 62'den uyarlanmıştır.)

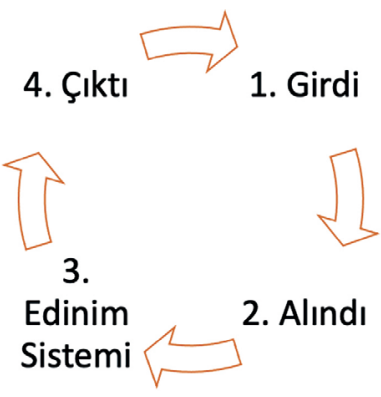


Bu şemaya göre öncelikle öğrenen kişi dışarıdan girdi alır. İlk olarak girdi kişinin zihninde işlenerek alındıya dönüştürülür. Bu noktada girdi üzerinde öğrenilmesi istenen yapılar vurgulanıp belirginleştirilerek öğrencinin fark etmesi sağlanır. Girdi yoluyla fark edilmesi sağlanan dil birimleri işleyen bellekte bir kere işlenip hipokampa aktarıldıktan sonra her seferinde yeniden bilinçli dikkat gösterilmesine gerek yoktur. Yalnızca anlamlı iletişim ortamlarında kullanılmaları örtük olarak işlenmelerini ve sağlamlaştırılmalarını sağlayacaktır. Girdi alındıya dönüşse de öğrenen kişi hâlâ dili edinmiş sayılmaz. Yani alındının tamamı otomatik olarak edinim sistemine aktarılmaz. $\mathrm{Bu}$ yüzden alındı var olan sistem içerisinde yeniden yapılandırılarak geliştirilmelidir. Geliştirilen alındı çıktı olarak üretilmeye hazırdır. Buna rağmen çıktılar, edinilmiş olan sistemin doğrudan yansıması değildir. Edinilmiş sistem kullanılarak dilin bir kısmı üretilebilir (Wulff ve N. Ellis, 2018; DeKeyser ve Botana, 2015; N. Ellis, 2011; Schmidt, 1990).

Bu döngü tekrar ettikçe ve herhangi bir yapı girdi içerisinde sık sık öğrencinin nörolojik sistemine girip çıktıkça öğrencinin dilde akıcılığı artar. (VanPatten ve Cadierno, 1993: 46). Beyin depoladığı açık bilgiyi pratik yaptıkça şemalar hâline getirmektedir. Bu sayede bir sonraki denemede bu bilgiye ulaşmak daha kolay hâle gelmektedir. Böylece zamanla dil daha akıcı hâle gelmektedir. Ancak dilin belli yapılarının akıcı kullanılması o bilginin örtük bilgi olduğu anlamına gelmemektedir. Bazı öbekler kontrollü bir akıcılık içinde kullanılıyor olabilir. Bilginin tamamen örtük bir hâle gelmesi için yani otomatikleşmesi için tamamen kontrolsüz bir akıcılık içerisinde kullanılması gerekmektedir. Bunun için de daha fazla örtük pratik gerekmektedir. Bu durum tıpkı bir aşçının aynı yemeği yaptıkça, onun malzemelerine daha hızlı ulaşması ve yemeği daha hızlı yapabilmesine benzemektedir. Bir müddet sonra aşçı yemeği gözü kapalı bile yapabilmektedir. Dili kullanan kişi de aynı anda başka işlerle uğraşırken bile dikkat kesilmeden o dili kullanabiliyorsa bilgi gerçek anlamda örtük hâle gelmiş demektir. Dilde akıcılık matematik derslerinden bir örnekle de açıklanabilir. Matematik’te önce $3+3+3+3=12$ olduğunu öğreniriz. Ancak her seferinde bunu bu şekilde ifade etmemize gerek yoktur. Daha akıcı ve ekonomik olmak için 3x4=12 şeklinde dememiz de yeterlidir (N. Ellis, 2005; Krashen ve Terrell, 1998; Schmidt, 1990). Günlük hayatta ana dilinde bir şeyler dinlerken aynı anda başka bir işle uğraşmak yabancı dildekine göre daha kolaydır. Bunun sebebi bu bilginin çoktan otomatikleşmiş olmasıdır. 


\section{Sonuç ve Öneriler}

Bu çalışmada 'dil eğitimi' öğretim, öğrenim, edinim gibi kavramları içine alacak şekilde kullanılmaktadır. Dil doğal bir ortamda edinilebileceği gibi bilinçli bir dikkatle öğrenilebilir ya da programlı bir şekilde öğretilebilir. Birçok durumda bu üçü birlikte olmaktadır. Sınıf ortamında dil eğitimini düşündüğümüzde, sınıflar dil öğrenme kaynaklarından yalnızca biridir. Dil öğrenen bir öğrenci eğer o ülkede yaşıyorsa (ikinci dil durumu) sokakta, yaşamıyorsa bile (yabancı dil durumu) internet kaynaklarından (filmler, web siteleri vs.) dile maruz kalmaktadır.

Açık ve örtük bellek (dolayısıyla bilgi ve öğrenme) tasnifleri dil eğitiminde teoride ve uygulamada birçok yaklaşımın ortaya çıkmasına sebep olmuştur. Çünkü bütün yaklaşımların temelinde bilginin nasıl bir bilgi olarak algılandığı vardır. Yukarıda her iki bellek türünün dil eğitiminde ortaya çıkardığı yaklaşımlar karakterize edilerek açıklanmış olsa da açık ve örtük bellek tasnifleri dil eğitiminde uygulamada birçok soru işaretlerini beraberinde getirmektedir. Aşağıdaki paragraflarda bellek tasniflerinin dil öğrenme pratiğine (sınıfta olsun sınıf dişında olsun) yansımaları çeşitli sorularla ortaya konulmaktadır.

Dil eğitiminde hedef ne olmalıdır? Çalışma boyunca belirtildiği gibi dil öğrenme konusunda nörobilim merkezli çalışmaların da etkisi ile farklı teorik pozisyonlar alınmışsa da dil öğrenenlerin iletişime dönük etkinliklere odaklanması ve örtük bilgilerini geliştirmeleri konusunda görüş birliği vardır. Çünkü tamamen örtük de olsa, açıktan örtüğe doğru da gitse dilde gerçek anlamda akıcılığı ve özgüveni sağlayan örtük türdeki bilgidir (R. Ellis 2005: 214).

Örtük ve açık dil öğrenimi birbirini yok sayan değil, birbirini besleyen iki öğrenme biçimi olarak görülmelidir. Her ikisi de dil yetkinliğinin farklı taraflarını beslemektedir. Dilde girdi ve çıktı döngüsü açık ve örtük bilginin bir araya getirilmesi için önemli bir avantaj sağlamaktadır. Örtük ve açık öğrenme birlikte düşünüldüğünde dil öğrenimi ve öğretimi için önemli katkılar yapabilir. Sınıfta dil öğretimi açısından düşünüldüğünde, öğretmenler ders programlarını girdi ve çıktı döngüsü ile uyumlu şekilde kurgulayarak öğrencilerini anlamlı girdilere, anlamlı çıktılara maruz bırakarak aynı zamanda yapılara da odaklanarak öğrenmelerini sağlayabilir, akıcılıklarını geliştirebilirler. Başarılı bir D2 öğretimine sınıf dışındaki kaynakları sınıfa doğru bir şekilde entegre ederek ulaşılabilir (N. Ellis, 2005: 339-40; Pienemann, 1989: 53).

Bu noktada 'etkileşimsizlik' görüşünün savunduğu gibi evrensel gramerin kendi ajandası dil öğretimi sürecine direnç gösterecektir. Literatürde bu durum 
‘öğretilebilirlik' ya da ‘öğrenilebilirlik” kavramları ile karşımıza çıkmaktadır. Buna göre öğretimin ancak ve ancak öğretilecek birim öğrencinin evrensel gramerinde (edinim sisteminde) edinim noktasına ulaşmışsa işe yarayacağı düşünülmektedir. Bunun dışında öğretim, geleneksel olarak düşünüldüğü gibi, bütün bir öğrenme sürecini değiştiremez. Öğretim bu açıdan doğal edinim sistemi tarafından kısıtlanmaktadır. Öğrenen kişi kendisine sunulan birimleri edinmeye hazırsa öğretim işe yarayabilir. Ancak literatürde bir dilin bütün birimlerinin öğretime direnç göstereceğine dair bir kanıt yoktur. Bu tür birimler genellikle karmaşık ve soyut olan birimler olmaktadır. Bir anlamda dilde sert kayalar ve yumuşak kayalar vardır. Sert kayaları parçalamak zorken yumuşak kayalar hâlâ parçalanabilir (VanPatten ve Cadierno, 1993: 45). Bu tür birimlerle ilgili Pienemann (1989: 60-61) öğretimin işe yaramadığı endişesine kapılmaya gerek olmadığını belirtmektedir. Öğrenci yeteri kadar dile maruz kaldığında o birimleri de öğrenmiş olacaktır.

Yine Pienemann (1989: 53) öğretim ile edinim sisteminin birbiriyle örtüştürülebileceği üzerinde durmuştur. Buna göre bir dilin edinim aşamaları çıkarılıp öğretim programları da buna göre düzenlendiğinde, yani öğrencinin bir sonraki öğrenme probleminin ne olacağı kaba hatlarıyla tahmin edilebildiğinde başarılı bir dil öğretimi gerçekleştirilmiş olacaktır. Krashen ve Terrell (1989: 29) İngilizcenin gramatik morfemlerinin D2 öğrencileri açısından ediniminin ortalama bir sıralamasını vermektedir. Buna göre ING (progressive), Plural, to be gibi yapılar daha önce edinilirken Regular Past, III. Singular (-s), Possessive (-s) gibi yapılar daha sonra edinilmektedir. Öğretim programlarının daha başarılı olması için Türkçe için de bu tür çalışmalar yapılabilir.

Frensch ve Rünger de (2003: 14) dilde A biriminin örtük olarak öğrenilebiliyor olmasının B biriminin de aynı şekilde öğrenilebileceği anlamına gelmediğini ifade etmektedir. Bu açıdan karmaşık olan birimleri örtük olarak öğrenmek mümkünken daha basit olanlar açık olarak öğrenilebilir.

Öğretmen yetiştiren programların gereklilikleri neler olmalıdır? Açık bilgi dil hakkında malumat sahibi olmayı ifade ederken örtük bilgi dili akıcı olarak kullanabilmeyi ifade eder. O hâlde dil hakkında malumat sahibi olmak ile dili tıpkı bir arabayı kullanır gibi kullanabilmek iki farklı olgudur.

İster yabancı dil olarak ister ana dili olarak olsun dil öğrenirken hedef, dili kullanmaksa dile bir nesne gibi değil, bir beceri gibi yaklaşılmalıdır. Bir tarih ya da coğrafya dersinde öğrenilen kavramlar üzerine konuşulabilir. Örneğin Türkiye’nin 
coğrafi özellikleri malumat sahibi olunabilecek ve üzerinde konuşulabilecek bir konudur. Fakat dil derslerinin içeriği tarih ya da coğrafya dersleri gibi inceleme konusu yapılamaz. Dilin bilgisine ulaşmak coğrafya derslerindeki bilgiye ulaşmak kadar kolay değildir. Çünkü dili gerçek anlamda (örtük olarak) kullanabilmek için ders kitaplarındaki bilgiye ulaşmak yeterli olmayacaktır. Bunun için dilin zihindeki temsiline ulaşmak gerekmektedir. Ders kitapları ya da öğretmenler bu temsilin ancak bir kısmını yansıtabilirler; bir anlamda buz dağının çok küçük bir kısmını.

Dili zihnî bir temsil olarak ifade ettikten sonra VanPatten (2019) dil öğretmeni olabilmek için herhangi bir dili bilmenin yeterli görülmesini eleştirmektedir. Buna göre dil öğretmenlerinin öğrettikleri dili bilmeleri gerektiği gibi dil olgusunu soyut anlamda da bilmeleri gerekmektedir (viii). Söz gelimi bir Türkçe öğretmeni olabilmek için yalnızca Türkçeyi bilmek yeterli görülmemelidir. Bir Türkçe öğretmeni Türkçeyi bildiği gibi zihinde soyut bir temsil olan dil olgusu hakkında da bilgi sahibi olmalıdır. Bu veri öğretmen yetiştiren programların dersleri arasına disiplinler arası bakış açısıyla öğrencilere hem birden fazla dille Türkçeyi karşılaştırabilecek hem de soyut olarak dilin ne olduğu ile ilgili formasyon kazandırabilecek dersler koymaları gerektiğini göstermektedir. $\mathrm{Bu}$ anlamda Türkiye'deki dille ilgili programların mezunlarının (Türkçe, İngilizce, Arapça vd. öğretmenlik programları, Dil ve Edebiyat Programları ya da Dilbilim programları) dil öğretmeni olmaya ne kadar uygun oldukları ders planları bu veriye göre taranarak incelenmelidir.

Ders kitaplarıyla gerçekten dil öğrenilebilir mi? Ders kitapları herhangi bir ders için akla gelen ilk araçtır. Dil sınıflarında da ders kitapları çok yaygın olarak kullanılmaktadır. Son dönemlerde teknolojinin gelişmesi ile internet kaynakları da kullanılmaya başlansa da ders kitaplarından hâlen tamamen vazgeçilebilmiş değil. Fakat bu çalışmada gösterildiği gibi dili akıcı olarak kullanabilmenin şartı örtük türde bilgi sahibi olmaksa açık bilgiye hizmet eden ders kitapları dil eğitiminin neresinde yer almaktadir?

Dil eğitiminde ders kitapları ancak açı bilginin örtük bilgiye dönüştürülebileceği görüşü ile savunulabilir. Buna göre ders kitaplarındaki açık bilgiler yoluyla dili pratik yaparak otomatikleştirebiliriz. Ancak açık öğretim deyince akla geleneksel gramer anlatımı gelmemelidir. Araştırmalar 'dikkat', 'bilinç' ve 'farkındalık' gibi kavramlara vurguda bulunarak açık öğretimin öğrencinin dikkatini konuya yöneltmek, farkındalığını artırmak olduğunu belirtmiştir. Psikolojide 'kavram öğrenme' üzerine yapılan çalışmalar insanların kavramları başka bir işaret/ipucu 
yardımıyla rastlantıya dayalı öğrenmekten daha kolay öğrendiklerini göstermiştir (Schmidt, 1990: 136). Bu açıdan düşünüldüğünde bilinçli dikkat, yalnızca maruz kalmaya göre öğrenme açısından her zaman daha işe yarar ve hızlandırıcıdır. Açık öğretim öğrencinin girdi içerisindeki yapılara olan dikkatini artırmak, odaklanmalarını sağlamak için kullanıldığında sinir sistemlerindeki yükü hafifletmekte, belleklerinde bilgiyi daha uzun süre depolanması için pekiştirmektedir (MacWhinney, 1997: 279).

Dil edinimi araştırmalarında ortaya konulan bu bulgulara göre hazırlanan ders kitapları öğrencilerin dikkatini girdi niteliğindeki metinler (video ya da görsel materyaller de metin olarak sayılabilir) üzerinden yapılara yöneltmekte, alıştırma ve etkinlikler yoluyla (yukarıdaki şekilde olduğu gibi) girdinin alındıya dönüştürülmesini, daha sonra edinim sisteminde işlenerek çıktılar üretilmesini ön görmektedir. Buna rağmen ders kitaplarında kullanılan alıştırma ve etkinlikler yukarıdaki döngüyü ne kadar etkili şekilde kullanabildikleri bakımından sorgulanmalıdır. Söz gelimi, Türkçe ders kitapları bu döngüye göre incelenerek dil edinimi için ne kadar işe yarar oldukları test edilebilir.

Dil bilgisi örtük bir bilgi ise nasıl ölçülebilir? Dil bilgisinin açık ve örtük bilgi olarak tasnifi dil testlerinin de sorgulanmasını sağlamaktadır (Bkz. Krashen ve Terrell, 1998). Dil öğrenme ister programlı bir şekilde (sınıf ortamında ya da kişi kendi kendine çalışarak) gerçekleşsin ister hayatın içinde kendiliğinden gerçekleşsin, her dil öğrenen kişi girdi ve çıktı döngüsünü tecrübe etmektedir. Bir kişi iletişim ortamlarında ortaya sözlü ya da yazılı bir çıktı koyabildiği sürece dili öğrenmiş sayılabilir. Bu yönüyle zihindeki gerçek dil bilgisi örtük bir bilgidir; çünkü iletişimin doğal akışı içerisinde ancak örtük bilgi kişiye pratik bir fayda sağlayabilir. Açık bilgi dilin bilgisi değil, dil hakkında bir bilgidir. Örtük bilgi bisikleti sürebilmekken, açık bilgi bisikletin nasıl sürüleceğini tarif edebilmek ama sürememektir. Bu yüzden bir dil ölçme aracı öğrencinin sahip olduğu gerçek bilgiyi ancak örtük türdeki bilgiye odaklanarak ölçebilir. Bu bilgi türü de dilin akııı ve doğru bir şekilde kullanılmasını ön görmektedir.

Söz gelimi, Türkiye'de akademik dil yeterliliğini ölçmek için düzenlenen standart testler kişilerin yalnızca okuduğunu anlama becerilerini ölçmektedir. Bunu yaparken gramer bilgisi de talep etmektedir. Ancak talep edilen bilgi dilin bilgisi değil, dil hakkındaki bilgidir. Bu sınavlar bir kişinin bisiklet sürüp süremediğine değil, bisiklet sürmeyi tarif edip edemediğine odaklanmaktadır. Bu yönüyle bu testleri geçmek kişinin gerçek anlamda dili bildiği anlamına gelmemektedir. Literatürde dil bilgisini süreç odaklı ve sonuç odaklı değerlendirmek için çok farklı yaklaşım ve uygulamalar mevcutsa da bu çalışmanın konusu olmadığından detaylara girilmemiştir. 


\section{Kaynakça}

Bialystok, E. (2011). How analysis and control lead to advantages and disadvantages in bilingual processing. Implicit and explicit language learning: Conditions, processes, and knowledge in SLA and bilingualism, 49-58.

Dekeyser, R. \& Botana, G. (2015). The Effectiveness of Processing Instruction in L2 Grammar Acquisition: A Narrative Review. Applied Linguistics, 36(3). 290-305.

Ellis, N. C. (2005). At the interface: Dynamic interactions of explicit and implicit language knowledge. Studies in second language acquisition, 27(2), 305-352.

Ellis, N. C. (2008). Implicit and explicit knowledge about language. Encyclopedia of language and education, 6, 1-13.

Ellis, N. C. (2011). Implicit and explicit SLA and their interface. Implicit and explicit language learning: Conditions, processes, and knowledge in SLA and bilingualism, 35-47.

Ellis, R. (2005). Principles of instructed language learning. System, 33(2), 209-224.

Ellis, R. (2006). Current Issues in the Teaching of Grammar: An SLA Perspective. TESOL Quarterly, 40(1), 83-107.

Frensch, P. \& Rünger, D. (2003). Implicit learning. Current Directions in Psychological Science, 12(1), 13-18.

Krashen, S. D. \& Terrell, T. D. (1998). The Natural Approach Language Acquisition in the Classroom. UK: Prentice Hall International.

Lenet, A. E., Sanz, C., Lado, B., Howard, J. H., Howard, D. V., \& Leow, R. P. (2011). Aging, pedagogical conditions, and differential success in SLA: An empirical study. Implicit and explicit language learning: Conditions, processes, and knowledge in SLA and bilingualism, 73, 84 .

Leow, R. P., Johnson, E., Zarate-Sandez, G., \& Sanz, C. (2011). Getting a grip on the slippery construct of awareness: Toward a finer-grained methodological perspective. Implicit and explicit language learning: Conditions, processes, and knowledge in SLA and bilingualism, 61-72.

Littlemore, J. (2009). Applying cognitive linguistics to second language learning and teaching. UK: Pallgrave Macmillan.

MacWhinney, B. (1997). Implicit and explicit processes: Commentary. Studies in Second Language Acquisition, 19(2), 277-281.

Onan, B. (2011). Anlama sürecinde Türkçenin yapısal işlevleri. Ankara: Nobel Akademik Yayınc1lik. 
Pienemann, M. (1989). Is Language Teachable? Psycholinguistic Experiments and Hypotheses. Applied Linguistics, 10(1), 52-79.

Reber, A. S. (2011). An epitaph for grammar: An abridged history. Implicit and explicit language learning: Conditions, Processes, and Knowledge in SLA and Bilingualism, 23-34.

Sanz, C. \& Leow, R. P. (2011). Introduction. Implicit and Explicit Language Learning: Conditions, Processes, and Knowledge in SLA and Bilingualism, 1-6.

Schmidt, R. W. (1990). The Role of Consciousness in Second Language Learning. Applied Linguistics, 11(2), 129-58.

Van Patten, B. (2019). The Nature of Language: A Short Guide to What's in Our Heads. American Council on the Teaching of Foreign Languages (ACTFL).

Vanpatten, B. (2011). Stubborn Syntax: How it Resists Explicit Teaching and Learning. Implicit and Explicit Language Learning: Conditions, Processes, and Knowledge in SLA and Bilingualism, 9-21.

VanPatten, B., \& Cadierno, T. (1993). Input processing and second language acquisition: A role for instruction. The Modern Language Journal, 77(1), 45-57.

Wulff, S. \& Ellis, N. C. (2018). Usage-based approaches to second language acquisition. Bilingual cognition and language: the state of the science across its subfields, 54, 3756. 